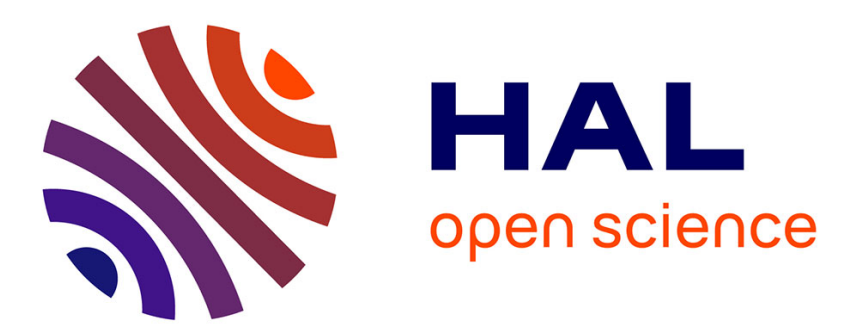

\title{
Managing Planned Disruptions of Mass Transit Systems
} Zoi Christoforou, Etienne Corbille, Nadir Farhi, Fabien Leurent

\section{To cite this version:}

Zoi Christoforou, Etienne Corbille, Nadir Farhi, Fabien Leurent. Managing Planned Disruptions of Mass Transit Systems. Transportation Research Record, 2016, 2541, pp 46-55. 10.3141/2541-06 . hal-01386790v2

\section{HAL Id: hal-01386790 \\ https://hal.science/hal-01386790v2}

Submitted on 9 Nov 2016

HAL is a multi-disciplinary open access archive for the deposit and dissemination of scientific research documents, whether they are published or not. The documents may come from teaching and research institutions in France or abroad, or from public or private research centers.
L'archive ouverte pluridisciplinaire $\mathbf{H A L}$, est destinée au dépôt et à la diffusion de documents scientifiques de niveau recherche, publiés ou non, émanant des établissements d'enseignement et de recherche français ou étrangers, des laboratoires publics ou privés. 


\section{MANAGING PLANNED DISRUPTIONS OF MASS TRANSIT SYSTEMS}

Zoi Christoforou (corresponding author)

Assistant Professor, Laboratoire Ville Mobilité Transport, Ecole Nationale des Ponts et Chaussées, 6 et 8 avenue Blaise Pascal, Cité Descartes, Champs-sur-Marne, F-77455, Marne-la-Vallée Cedex2, France, tel. +33181668872, fax: +33181668800, email: zoi.christoforou@ enpc.fr

\section{Etienne Corbillé}

MScStudent, Ecole Nationale des Ponts et Chaussées, 6 et 8 avenue Blaise Pascal, Cité Descartes, Champs-sur-Marne, F-77455, Marne-la-Vallée Cedex2, France, tel. +33181668872, fax:

+33181668800, email: etienne.corbille@eleves.enpc.fr

\section{Nadir Farhi}

Researcher, Université Paris-Est, Ifsttar/Cosys/Grettia,14 - 20 boulevard Newton, Cité Descartes, Champs-sur-Marne, F-77447, Marne-la-Vallée, Cedex 2, France, tel. +33181668704, fax: +33181668800, email: nadir.farhi@ ifsttar.fr

\section{Fabien Leurent}

Professor, Laboratoire Ville Mobilité Transport, Ecole Nationale des Ponts et Chaussées, 6 et 8 avenue Blaise Pascal, Cité Descartes, Champs-sur-Marne, F-77455, Marne-la-Vallée Cedex2, France, tel. +33181668872 , fax: +33181668800 , email: fabien.leurent@enpc.fr 


\begin{abstract}
Unplanned disruptions of rail transit networks have been extensively studied. Planned disruptions for works are essentially different mainly due to their longer duration that allows passengers to build alternative route choice strategies. The literature on this topic remains scarce. We propose a novel methodology that enables operators to evaluate different disruption management schemes and to obtain explicit estimations of travel times, passenger comfort flows, and levels of service. Statistical tools are used for the evaluation of the different strategies. We illustrate the methodology through a large-scale application to a real line disruption in Paris, France. The disruption took place in July 2015 and was due to network maintenance works. It affected the major suburban railway line RER-A which counts over 1,000,000 trips on a typical working day. Results indicate that the disruption would have significantly increased the generalized cost (GC) of passengers if no action was taken. The operator's disruption management scheme included bus bridging and frequency increase on alternative routes. The evaluation of this plan shows that it restored the average GC over the whole network. Passengers initially using the disrupted line experienced increased GC by using alternative longer routes. Passengers initially using those alternative routes experienced lower GC thanks to the frequency increase. Finally, capacity problems are observed on the buses assuring the bridge of the disrupted link.
\end{abstract}




\section{INTRODUCTION}

On one hand, urban population is rapidly growing and travel demand is increasing in city centers worldwide. On the other hand, urban space is scarce and new road infrastructure becomes costly. As a result, urban agglomerations suffer from heavy congestion, long delays, and serious travel time variability. Commuters turn to public transit systems that also begin to suffer from capacity phenomena. Heavy reliance on mass transit systems and operations at capacity levels make transit systems very vulnerable to disturbances. Simple service disruptions lead to undesirable outcomes such as delay propagation and passenger inconvenience. Reliability and robustness of transit systems are major issues that receive the attention of both researchers and practitioners.

The link between transportation and city planning is known and well documented. Regarding public transport, planning includes a range of problems varying from strategic to operational level: network design, line planning, and timetabling (1). Traffic assignment models have long be used for planning purposes. These models provide an estimation of individual route choices based on a set of network and demand parameters such as origin-destination (OD) pairs, mode availability and capacity. We should note, though, that when used for planning purposes, assignment models are mainly static and consider only normal operating conditions. Regular maintenance, works and other disruptions are not integrated. In many cases, infrastructure capacity is not taken into consideration either.

However, disruptions occur regularly. Unplanned (or unforeseen) disruptions may be caused by natural disasters, terrorist attacks, accidents, medical emergencies, adverse weather, infrastructure or rolling stock failures (2). Planned (or foreseen) disruptions occur mainly due to strikes, special mega-events, maintenance and upgrade works. Disruptions differ significantly in respect to their magnitude and scale, the ir duration and impact. The impact concerns both demand and supply. In fact, behavioral changes (i.e. daily activities, departure time, modal and route choice) are observed during disruptions that may even alter mode choices in the long-term (2). On the supply side, operators have to assure the static and dynamic resilience of the network by developing and implementing disruption management schemes and programs (DRPs). Dynamic resilience refers to the capacity and time to recover after a shock and is mainly relevant to unplanned disruptions. Static resilience describes the ability of the system to operate under degraded conditions and is most relevant to planned events.

A key element to sustainable operations is robustness that assures low sensitivity to disturbances. Indexes for the network's robustness evaluation for the case of random failures ('mean indexes') and intentional attacks ('worst-case indexes') can be found in the literature (3). Resilience should also be included in economic models. In (4), the authors add at the cost function a term representing operator and passenger costs due to unplanned delays. The authors value the GC of nonscheduled delay more highly than either in-vehicle travel time or scheduled waiting time. Following the earlier indication in (5), they take a coefficient of 2.4 times the in-vehicle travel time.

Nevertheless, most agencies apply DRPs that do not account for user costs and do not assure system optimization. Unplanned short-term events are handled real-time with operators trying to minimize the disruption impact based on the ir experience and ad-hoc decision support tools. On the contrary, DRPs can be prepared and tested before a planned disruption occurs. DRPs are also relevant in the case of unplanned disruptions of long duration. As an example, the I-35W bridge over the Mississippi River collapsed in 2007 and interrupted the usual route of 140,000 daily vehicles for 66 days. The daily cost to users was estimated between $\$ 71,000$ and $\$ 220,000$ (2). Despite the numerous studies on unplanned disruption management, the literature on planned disruptions of mass transit systems remains scarce. Transit assignment tools have rarely been used for this purpose.

This paper proposes a novel methodology for the evaluation of DRPs using a traffic assignment model that accounts for capacity constraints and passenger comfort. This methodology can be implemented at all stages of the planning procedure to compare the robustness of different alternatives and the system's sensitivity to disturbances. We, first, adapt the OD matrix to the disruption characteristics. Then, we perform assignment under capacity constraints and estimate not only delay (due to frequency reduction and/or link removals)but also passenger comfort states (invehicle congestion, on-platform waiting times). Finally, we statistically compare results and quantitatively evaluate different DRPs. The proposed methodology is tested on a real transit network, the Ile-de-France network, which accommodates 8.3 million trips on a typical day(6). A major disruption on the suburban railway was planned for summer 2015 due to maintenance works (7). We apply the methodology to evaluate the DRP proposed by the operator. 
The remainder of this paper is organized as follows. Section 2 reviews the literature, section 3 explains the proposed methodology, section 4 presents the application to the Ile-de-France network, and section 5 discusses the results and draws conclusions.

\section{BACKGROUND}

Many researchers work on road traffic operations during short and long disruptions $(8,9)$. When a road link fails, it is usually quite simple to find alternative paths and reroute traffic. Severe delays may occur but the connection is assured. The objective is, then, to optimize the assignment procedure by minimizing delays. In the case of planned works, the problem becomes even simpler as alternative schemes can be tested and evaluated off-line through simulations as in (10).

In the case of rail transit networks, additional difficulties exist due to limited interconnections and overtaking possibilities. Unplanned disturbances may vary from minor incidents and slow-moving delays to major incidents that close entire track sections (11). In real-time contexts, operators face two main challenges: (i) the incident duration is not known in advance and(ii) the status of the network changes quickly (12). In (13), the authors propose a methodology to forecast the duration of disturbances and, thus, reduce their impact on the scheduled timetable. This framework can be used by operators as a decision aid tool. In (14), the authors propose an advanced decision support system to help dis patchers make real-time changes and to limit delay propagation. The network is divided into dispatching areas of limited size and various disruption scenarios are tested off-line. Performance is evaluated in terms of travel time, waiting times, train delay.

The optimal strategy also depends on the nature of the unplanned disruption. If a train is disabled, operators re-route commuters to the next train or to another mode and balance out the frequency of the remaining train service (15). In the case of complete line blockages, the re-routing also concerns trains while the frequencies of substitute lines increase. Buses or even taxis are used to assure the disrupted links. In (16), an overview of ad-hoc bus bridging services is provided and an efficient decision support system is proposed. If reserve buses are strategically located over the network, the response to disturbances can be further ameliorated (i.e. shortened). The optimal location can be obtained as a function of disruption type likelihood, passenger volumes, travel time to bus bridging termini, and so on (17). Another proactive recovery strategy is to optimally locate track crossovers as in (18) or to predefine measures in case of certain disruptions that operators can apply directly and achieve time savings (19). These techniques provide solutions for short-term disruptions or low-demand networks or require space that is not always available in dense urban areas.

The unplanned disruption management problem can be divided in three sub-problems:

(i) Timetable adjustment. It is commonly achieved by control strategies such as holding and short-turning $(20,21,22)$. The objective is either schedule-adherence for long headways or headwayadherence for high frequencies. Many researchers have proposed optimization-based algorithms for rescheduling including various elements in the objective function. In (20), the algorithm performs a depth-first search using an evaluation function to prioritize when conflicts arise and then branches according to predefined criteria achieving significant time savings. In (21), the objective function maximizes the number of recovered trips and guarantees a conflict-free timetable during the disruption. Delay is not constrained though. In (22), train delay is not constrained either but the objective function minimizes inconvenience to passengers that is defined as the sum of traveling time on-board, on-platform waiting time and number of transfers. This formulation may result to prolonged dwell times in order for trains to wait for passenger arrivals. Train capacity constraints are considered for both interstation segments and station tracks.

(ii) Evacuation of the 'blocked' passengers. Interactions between supply and demand are complex and the optimal strategy may be affected by demand conditions (23). An international survey across 71 transit agencies suggests that only $20 \%$ of the agencies have parallel transit systems that can evacuate passengers(24). Bus bridging seems to be the most common response but rarely do agencies keep a strategic vehicle reserve for this purpose. Thus, some researchers have expanded rescheduling algorithms to include passenger evacuation. In (25), the authors propose a rescheduling algorithm that has two interesting features: it accounts for the passengers' waiting while queuing on platforms and the time needed to implement a plan is quantified in the delay estimation. However, the user perspective and the in-vehicle comfort state are not taken into account. In (12), the passenger decision making is integrated and capacity is considered. Passengers make decisions about itineraries according 
to a logit model and then try to board a train serving that itinerary. This relaxation allows passengers to change their initial decisions and adapt to the changing environment. However, the information leading to mind-changes remains limited. On the contrary, traveler perception is shaped by the ir individual prior-knowledge, accumulated experience as well as information availability (26).

(iii) Rolling stock and crew rescheduling. Many optimization algorithms under availability constraints can be found in the literature (see for example 12,14) but are beyond the scope of this paper.

Planned disruptions differ from unplanned disruptions in many ways. A first 'chaotic' phase is observed immediately after an unplanned disruption. During this phase, operators and passengers have limited or no visibility of the cause, magnitude, and duration of the failure (19). This phase does not exist in the case of planned works especially when communication campaigns are in place. When unexpected incidents occur, an important segment of the demand is obliged to make en route rerouting and real-time decisions with limited information at-hand; whereas, during planned disturbances, the route is decided in advance. Information availability changes for the operators as well. Furthermore, the time horizon is entirely different and, so, system equilibrium may be possible for planned works but not for short disruptions. Also, planned disturbances allow operators to predict and assure the availability of necessary resources; both human and technical. Concluding, best strategies and DRPs differ significantly from one case to the other.

Despite the significant research on unplanned disruptions, very few researchers have worked on the optimization and evaluation of DRPs for short planned disruptions and even fewer on longer planned disruptions. In (23), the authors analyze effects on travel demand of different levels of degraded rail services during short disruptions. Their contribution is important as the authors consider both supply and demand. In particular, they introduce capacity constraints of rail vehicles and a FIFO approach for simulating the sequence of users boarding trains. They argue that mingling is not relevant in the case of major incidents on the network due to high crowding. In (27), the authors propose a holding control model based on rolling-horizon optimization capturing dynamics of running times and demand that can be applied to high-frequency transit disruptions. They consider both foreseen and unforeseen events under two control scenarios: naïve and informed control. They test these scenarios in a toy instance of a bus route having 20 stops per direction and find important performance improvements achieved by the informed control model. This model uses preemptive holding and other assumptions that can handle short disruptions but are unsuitable in the case of long disruptions of several weeks. In (28) we find a study for longer disruptions. The authors consider planned works in a mixed integer programming model that optimizes a production plan with regard to both trains and preventive maintenance. Thus, they estimate best traffic flow schemes given a fixed set of planned maintenance activities. However, passengers' point of view is not considered.

In conclusion, there is a complete absence of studies dedicated to disruption response planning and to the application of optimization techniques despite their potential utility to operators (1).Furthermore, studies on unplanned disruptions are macroscopic and do not always account for the infrastructure capacity and the resulting passenger comfort state. If capacity is not considered, the simulated failure effects tend to be calmed more rapidly than in real cases (23). Our contribution with respect to the existing literature may be summarized as follows:

- We study planned rail transit disruptions;

- We perform re-assignment considering both the supply and demand structure;

- We account for network capacity and passenger comfort;

- We propose a statistical evaluation of different strategies;

- We illustrate our findings for the case of a real disruption of a large-scale network.

\section{METHODOLOGY}

The proposed methodology consists of the following steps:

1) Supply 'deformation': adjusting the network to the planned disruption by removing links, adapting frequencies, adding new links for bus bridging, and so on;

2) Demand 'deformation': estimation of public transport modal share during disruption period;

3) Scenario building: alternative DRPs to be evaluated;

4) Assignment for each scenario using the model CapTA;

5) Statistical comparison of results. 
In (29) the authors present the case of a disruption at the Washington metro and study its impact upon demand. They conclude that a significant shift occurs towards other modes. Reassignment is thus necessary in order to estimate delays more accurately. We give below an overview of CapTA (Capacitated Transit Assignment), the transit assignment model used in this study for the reassignment. The reader can refer to (30) for a detailed description of CapTA, together with an application to the greater Paris area on a typical working day of 2010, including a special focus on the RER-A line: at the morning peak, the westbound passenger flow in central Paris amounts to more than 50,000 passengers per hour i.e. the line is equivalent to 25 motorway lanes at capacity load. It is thus even more important to model the full set of alternative routes and their own sensitivity to congestion.

The CapTA model has a three-layered architecture:

(i) The upper layer represents passenger route choice on a network of pedestrian links and transit legs - a leg being a pair of stations for access and egress along a given transit line. Every passenger is assigned to its least-cost hyperpath, in the framework of static, frequency-based, optimal strategy assignment.

(ii) The lower layer deals with vehicle runs along the service routes. Each such route is addressed on an individual basis, with an average vehicle that has given seat capacity, total in-vehicle capacity, and exchange capacity. The flows of boarding and alighting passengers are assigned to the vehicle along the stations that it serves, yielding in-vehicle passenger loads and comfort (with sitting priority according to chronology of passenger access to the vehicle). Moreover, the station dwell time depends on alighting and boarding flows in relation to exchange capacity - hence the run times by trip leg.

(iii) The middle layer addresses specific line issues. First comes the coordination of the service routes that make up the line, especially so for the RER-A line that has two eastern branches and three western branches grafted in a central trunk: this yields combined frequency and residual capacity by line leg. Then, the residual capacity at a given station is faced to the flow of willing-toboard people, assumedly mingled, in a special bottleneck model that yields average passenger wait time and vehicle boarding probability by leg, thereby determining the passenger load of each vehicle serving the station. Next, still by station, the occupancy of the vehicle track due to the dwell times associated to the routes that serve the station, together with the clearance times of the routes that do not stop there and the safety margins between the vehicles, is evaluated for the assignment period on the basis of the target frequency assigned to the routes. Whenever the demanded occupancy exceeds the period duration, a reduction ratio is applied to the target frequency, yielding a reduced frequency which is propagated downstream. Lastly, frequency reduction entails a related delay to subsequent trains: this is evaluated on the basis of a bottleneck formula and propagated upstream in a specific way.

To conclude, the CapTA model captures a wide range of traffic phenomena. These are integrated in a consistent way, owing to the leg representation. The state vector involves (i) passenger flows by link and destination, (ii) service frequency by route and node along it and (iii) vectors of strategy assignment by destination and current node. An equilibrium state must exist in theory. In practice, about one hundred iterations of a Method of Successive Averages enable one to get a traffic state with satisfactory convergence to equilibrium.

In the following section, we apply step-by-step the proposed methodology to a real disruption that took place in summer 2015 (7).

\section{APPLICATION TO THE RER-A PLANNED WORKS}

\section{Supply 'de formation'}

Greater Paris counts 41 million trips on a typical working day and over 12 million inhabitants that spend on average 1.3 hours for transportation every day. The public transport network is extensive and absorbs $20 \%$ of the total trips made. It consists of 14 metro lines, 4 suburban railway lines, 1,500 bus lines, 8 tramway lines, and 8 regional train lines. The most congested line is the suburban railway line RER-A that counts over 1,000,000 passengers on a typical working day. It crosses the region in an east-west direction and serves the major business center of La Défense.

RER-A infrastructure is ageing and serious maintenance works must be undertaken. A program of works was decided as shown in Figure 1. More information can be retrieved on the 
operator's website (7).In 2015, the RER-A closed between July $25^{\text {th }}$ and August $23^{\text {rd }}$. At the same time, another less important suburban line, the RER-C, partially closed between the stations Javel and Gare d'Austerlitz. The operator used replacement buses for the two closures and increased frequencies on substitute modes (i.e. mainly metro line 1) at winter frequency levels and beyond. This was not the case for other lines that operated at reduced summer frequencies as usual. The annual capacity reduction when passing from winter to summer schedules is generally estimated at $30 \%$. All of these supply changes have been integrated in the network building of CapTA.

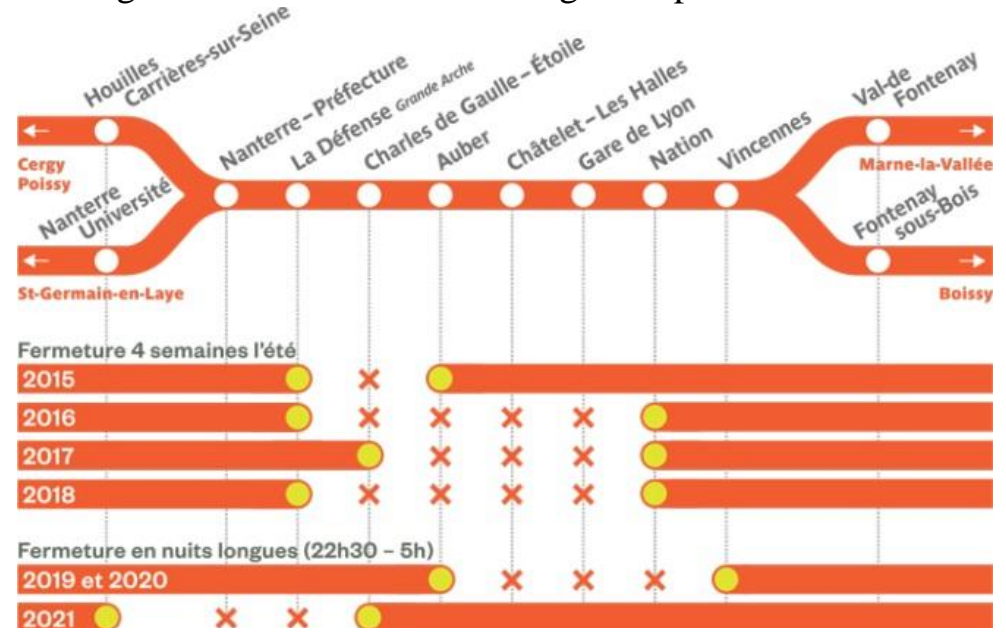

FIGURE 1Planne d works on the RER-A.

\section{De mand 'de formation'}

The timing of works during French summer school vacation imposes the adjustment of the OD 'winter' matrix downwards. We estimated summer demand using the recent household travel survey (EGT 2010) that is publicly available and a series of hypotheses: 'studies' were removed from travel motives, 'work' was reduced by $35 \%$, and tourist levels were upgraded. In total, we found a $40 \%$ reduction when passing from winter to summer demand. Figure 2 illustrates the origins of all trips to 'La Défense' station after the adjustment of demand. Figure 2 reveals that most incoming flows start from the inner city center and will be, thus, affected by the disruption.

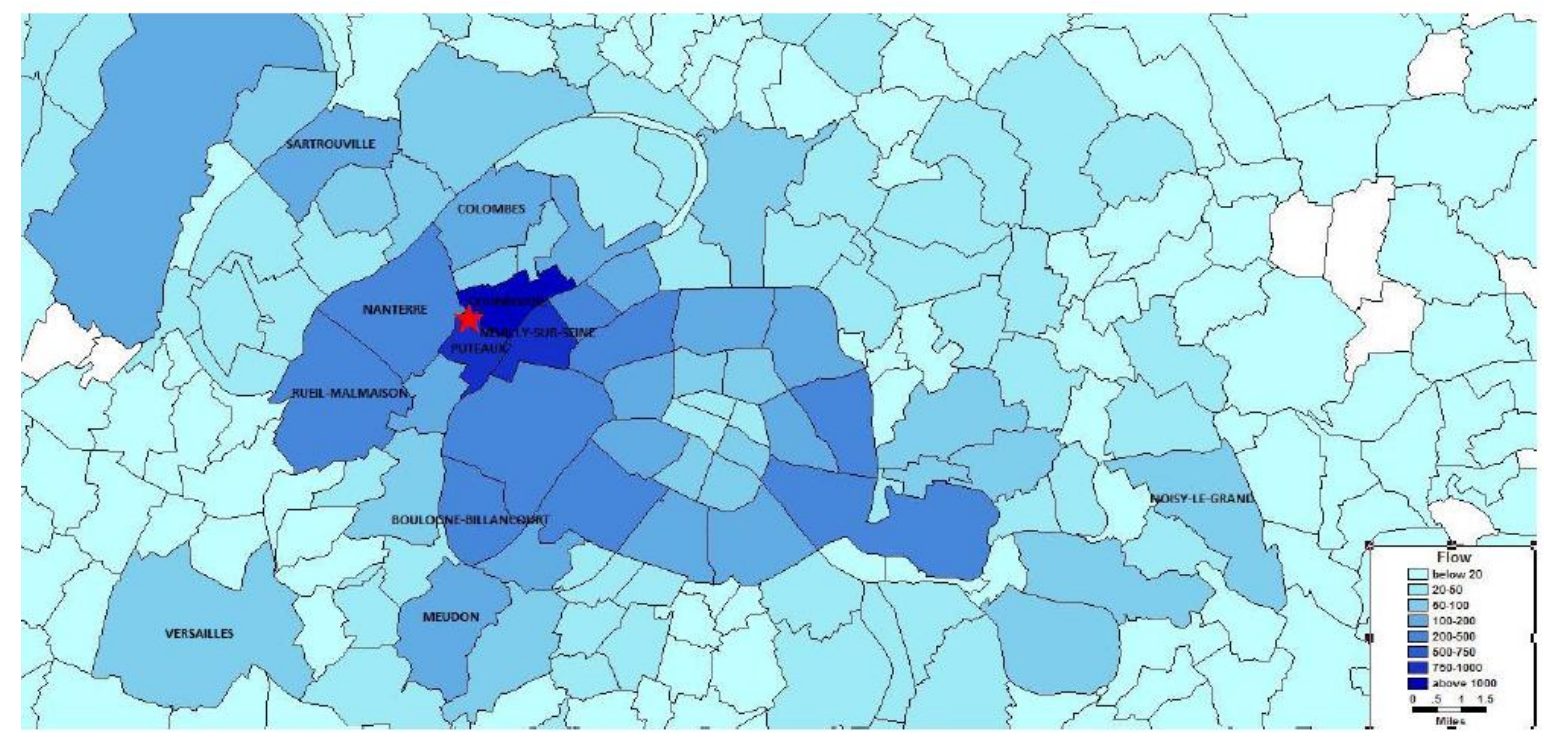

FIGURE 2 Passenger flows to 'La Défense' per origin during dis ruption 


\section{Scenario B uilding}

The following scenarios were simulated once without capacity constraints (sub-scenarios-a) and once with capacity constraints (sub-scenarios-b):

-S0: Winter demand, winter supply, without disruption;

-S1: Summer demand, summer supply, without disruption;

-S2: Summer demand, summer supply, with 2015 disruption;

-S3: Summer demand, with 2015 disruption with winter supply and bus bridging.

S0 represents the business-as-usual operating plan for wintertime and S1 represents the business-as-usual operating plan for summertime when both demand and supply are decreased. The supply is decreased mainly by frequency reduction. S2 refers to the 2015 summer disruption if no action is taken. S3 represents the official operational plan that has been prepared by the operator (i.e. the RATP). This plan includes the maintenance of the winter frequency for Metro Line 1 and the operation of a bus bridging line linking Auber to La Défense.

\section{Assignment and Statistical Analys is}

Simulation results provide passenger volume (v)and volume-to-capacity (v/c) ratio per link as well as the GG per OD-pair. In CapTA, the GC is calculated as the sum of travel time (including transfer), waiting time, and comfort state. Waiting time estimates are a function of frequencies and vehicle capacities. Two in-vehic le comfort states are considered: seated vs. standing. In total, 3,048,317 ODpairs were analyzed with 62,728 network arcs. Figure 3 shows the frequency distributions of the GC and the flows for S0a. Table1 presents some descriptive statistics for the datasets obtained. We first observe that the sample is not normally distributed but very skewed. Let us now compare between the a- and b-variants of each scenario. Table 1 reveals that if link capacity is not considered (a-variants) the v/c ratio largely exceeds the $100 \%$ which is unrealistic. The latter is mainly the case when the disruption takes place (under S2 and S3) where we obtain a v/c ratio of $721 \%$. Consequently, ignoring capacity when performing transit assignment leads to erroneous results, especially when we have line closures. This is also illustrated in Figure 4 where we plot the GC of the a-variants over the GC of the b-variants. As a result, in the remainder of this paper we only consider the b-variants of the four scenarios.
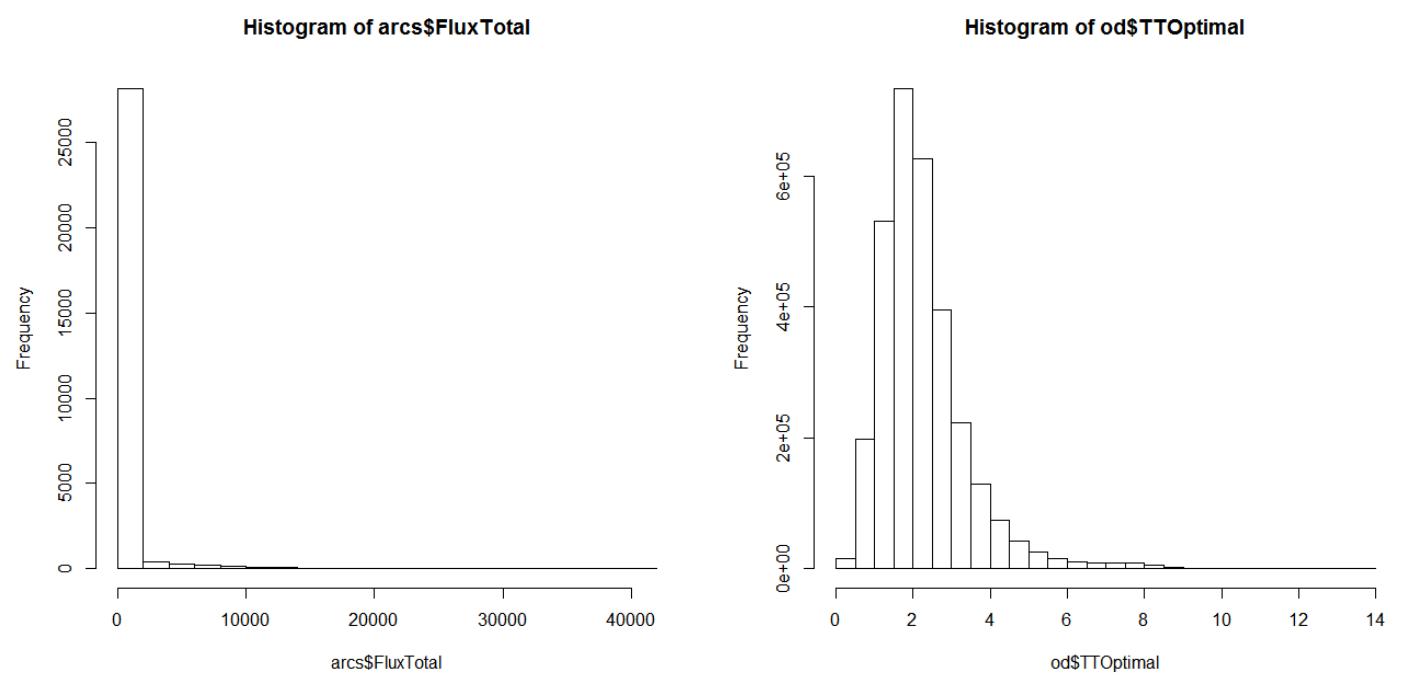

FIGURE 3 Frequency dis tribution for (a) passenger flows per arc and (b) GC per OD. 
TABLE 1Descriptive Statistics for Simulation Results per Scenario.

\begin{tabular}{crrrr}
\hline Scenario & \multicolumn{2}{c}{ V/C per link } & \multicolumn{2}{c}{ GC per OD } \\
\hline & average & SD & average & SD \\
S0a & $153,7 \%$ & $8,4 \%$ & 2,30 & 1,15 \\
S0b & $108,1 \%$ & $8,0 \%$ & 2,24 & 1,43 \\
S1a & $645,2 \%$ & $33,7 \%$ & 2,11 & 1,04 \\
S1b & $132,5 \%$ & $8,1 \%$ & 2,21 & 1,43 \\
S2a & $721,2 \%$ & $39,3 \%$ & 2,08 & 1,02 \\
S2b & $134,9 \%$ & $9,1 \%$ & 2,48 & 1,75 \\
S3a & $115,0 \%$ & $6,7 \%$ & 2,08 & 1,02 \\
S3b & $94,0 \%$ & $6,3 \%$ & 2,17 & 1,41 \\
\hline
\end{tabular}
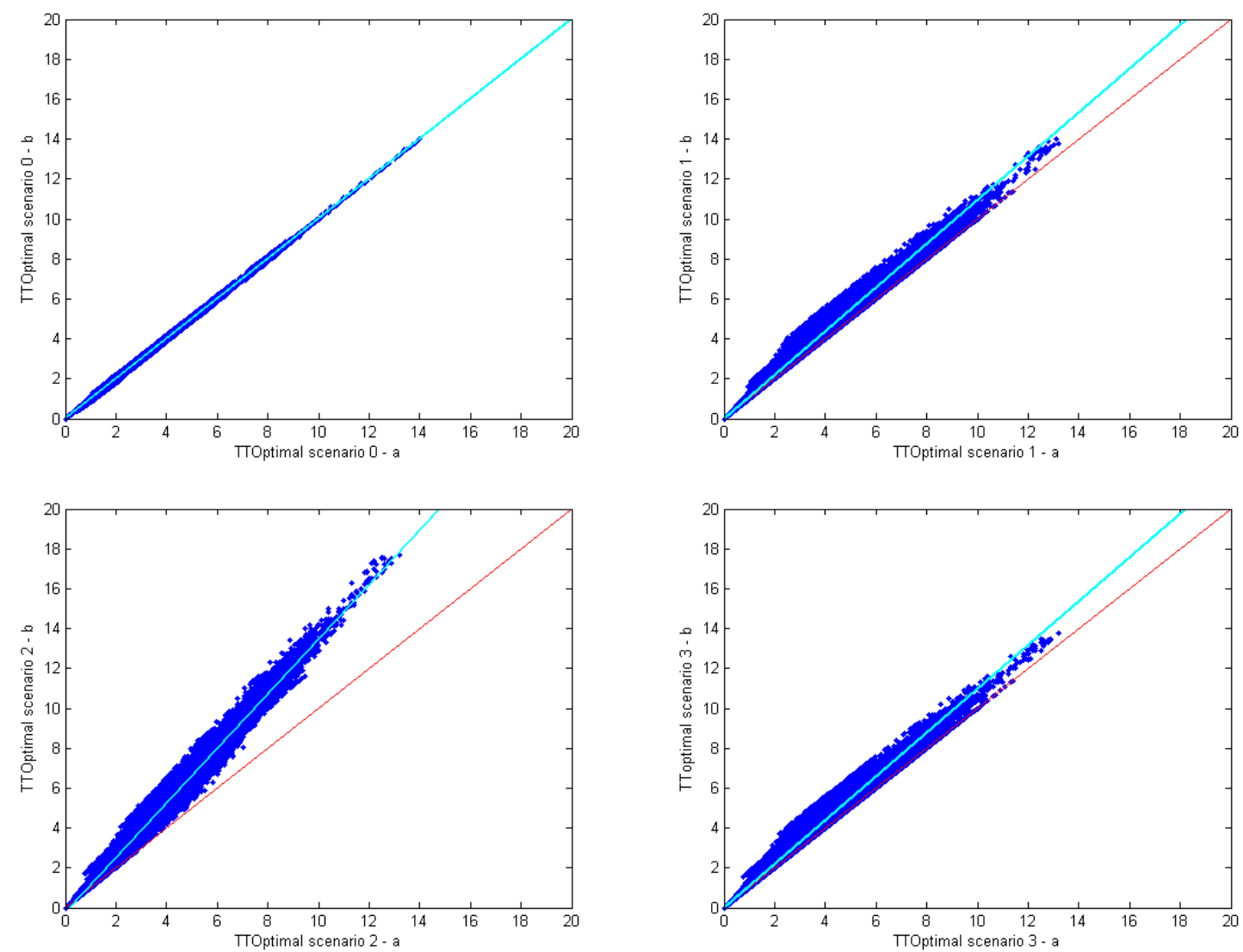

FIGURE 4 Comparison of the GC of the a- over the b-variants for S0, S1, S2, S3.

Focusing to the analysis of the capacitated assignments, we obtain Figure 5 that gives the frequency distributions of the GC. Under normal operating conditions (S0,S1), the GC is higher during wintertime versus summertime but the two distributions have a similar form. This can be intuitively explained by the lower level of service and the congestion phenomena due to increased demand. If the line closure happens and no action is taken (S2), the GC takes its maximal value. It is not only higher than the summer GC (S1) but even higher than the winter GC (S0). It also shows a significantly greater variance as many OD pairs exist that have a GC of around 10 . We can reasonably assume that these OD-pairs correspond to the affected routes. This variance disappears under S3 when the DRP is implemented and the average GC becomes even lower than the one of normal operating conditions. The mean percentage GC error for S2b versus S3b is of 10.23\%, for S2b versus S1b of $9.52 \%$, and of $\mathrm{S} 1 \mathrm{~b}$ versus S3b of only $0.49 \%$. The difference between S2 and S3 can be easily visualized in Figure6 that was produced with the TransCAD software. In Table 2, pairs of scenarios are compared in term of 
GC using two statistical indicators: MPE (mean relative prediction error) and RMSE (root mean squared relative prediction error).
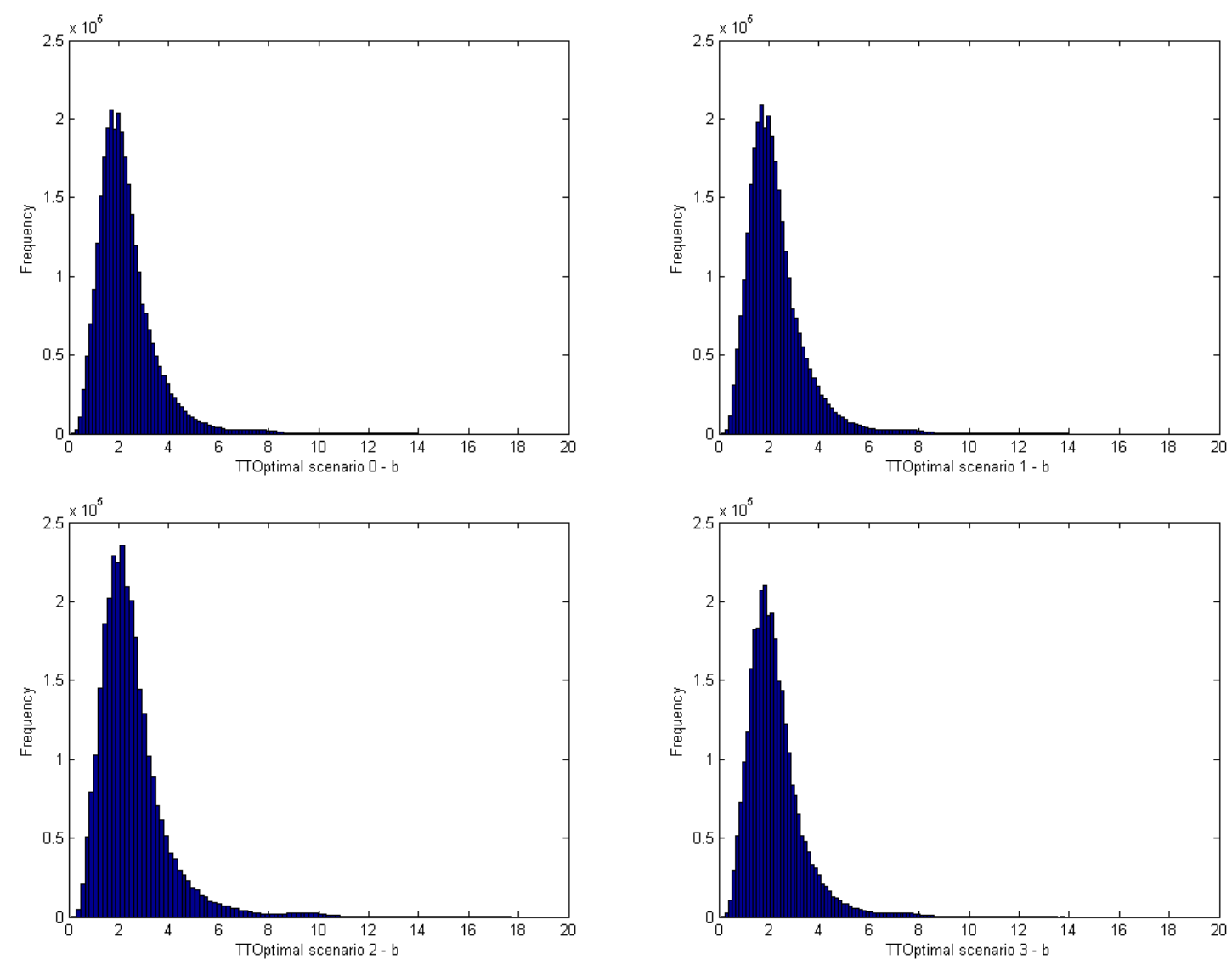

FIGURE 5Frequency distributions of GC for S0b, S1b, S2b, S3b.
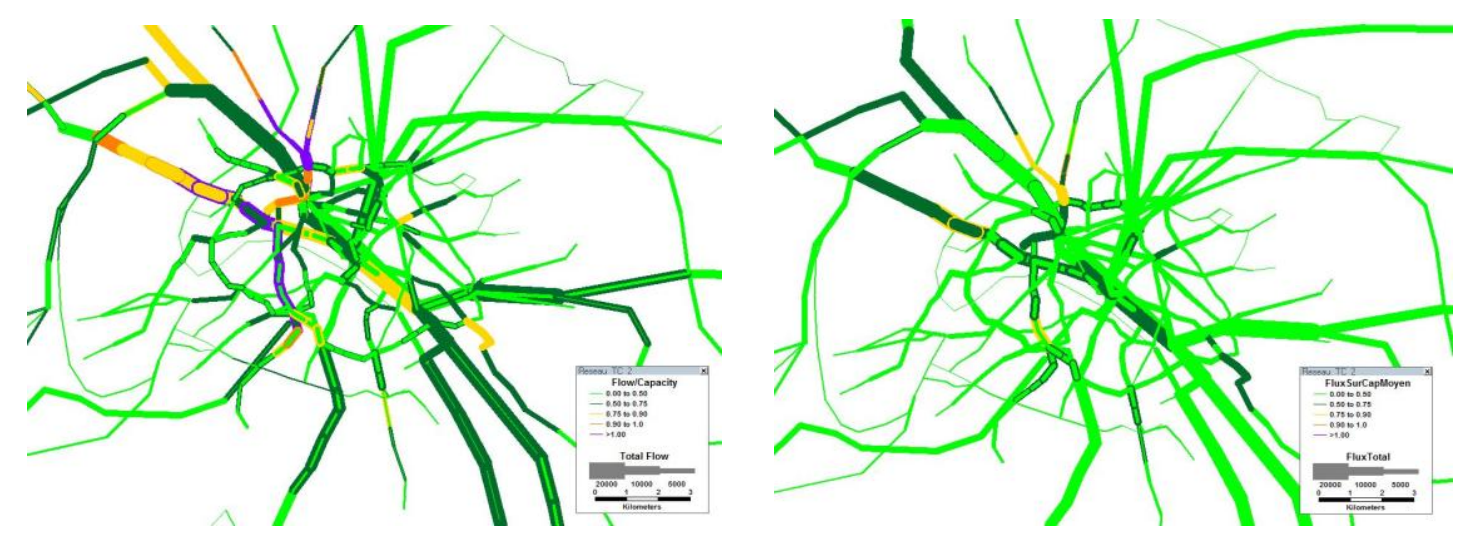

FIGURE 6Passenger (v/c) for S2b and S3b.

\section{Focus on selected itineraries}

In this section, we focus on the OD-pairs that are expected to be mostly affected by the disruption and we explore the efficiency of the planned management scheme (S3). Table 2 gives the GC for selected origins and destinations: La Défense (Paris major business district), Nanterre Université (important attraction pole), Les Halles (the major transit hub of Paris), and the $8^{\text {th }}$ arrondissement (where the disruption is located). Comparing S2 to S3, we observe that, indeed, the planned scheme seems to alleviate the problem for all itineraries. Nevertheless, it becomes obvious that the passengers using the links that are directly affected by the disruption will experience increased GC compared to the normal 
operating conditions under summer (S1) or even wintertime (S0). They will opt for alternative longer routes as a second best choice given that public transport demand has a low elasticity and that travel time differences (between RER and metro) are not very high. However, the capacity of the links serving alternate routes will not be exceeded as previously. The fact that the average GC over the network is equal to the GC under normal operating conditions (see previous section) implies that the GC of some other passengers will decrease. These passengers are the ones who were initially using the alternative routes whose frequency will increase according to the management disruption scheme. Their travel time decreases (increased frequency) without significant loss of level of service as capacity is not exceeded.

TABLE 2 Ge ne ralize d cost (GC) per s cenario for se lected itine raries.

\begin{tabular}{lcccccc}
\hline & $\begin{array}{l}\text { Destination: } \\
\text { La Défense }\end{array}$ & $\begin{array}{l}\text { Origin: } \\
\text { La Défense }\end{array}$ & $\begin{array}{l}\text { Destination: } \\
8^{\text {th }} \\
\text { arrondissement }\end{array}$ & $\begin{array}{l}\text { Destination: } \\
\text { Nanterre Univ }\end{array}$ & $\begin{array}{l}\text { Destination: } \\
\text { Les Halles }\end{array}$ & $\begin{array}{l}\text { Origin: } \\
\text { Les } \\
\text { Halles }\end{array}$ \\
\hline S0b & 1.24 & 0.80 & 1.17 & 1.67 & 1.10 & 0.69 \\
S1b & 1.20 & 0.78 & 1.14 & 1.63 & 1.08 & 0.67 \\
S2b & 1.44 & 0.90 & 1.24 & 1.85 & 1.17 & 0.76 \\
S3b & 1.29 & 0.83 & 1.13 & 1.69 & 1.07 & 0.71 \\
\hline
\end{tabular}

\section{CONCLUSIONS}

Planned disruptions of railway transit systems occur frequently and are costly to both users and operators. Despite the numerous studies on unplanned railway disruptions, few are the studies investigating planned railway disruptions. In this paper, we propose a novel methodology that enables operators to evaluate different disruption management schemes and to obtain explicit estimations of travel times, passenger comfort flows, and levels of service. We apply this methodology to a real large-scale disruption. Results indicate that the operator's plan will indeed restore the network's performance on average. However, when looking closer, we find that some passengers will experience higher GC and some others lower.

The added value of this paper is manifold. We provide quantitative evidence of the necessity of performing re-assignment when elaborating a DRP. Otherwise, important network effects may be neglected. Also, we prove that, if capacity constraints are ignored, results are entirely unrealistic. Furthermore, we show that all macroscopic analyses at the network should be combined with microscopic analyses at the level of the affected routes. Moreover, we show the inefficiency of bus bridging strategies in the case of large-scale and long disruptions when passengers can plan in advance their routes. Besides, bus capacities remain marginal compared to the metro and cannot accommodate demand. Bridging buses are interesting options for passengers that are not familiar to the network (such as tourists) or in cases where the landscape does not allow for any other alternative (such as for a major water crossing).

Finally, our research suffers from some shortcomings. Modal choice was not considered even if shifts towards private cars could occur. The role of information campaigns was not discussed and its impact upon the assignment was not investigated. At this point of time, we ignore the real-time guidance that the operator will choose to provide (itinerary calculators and so on). On the modeling side, we cannot be sure that the assignment is exact as the system's equilibrium will not necessarily be attained during the first days of the disruption. We intend to explore these issues and, also, compare our simulation results to what actually happened during the disruption using smart card validation data and other measurements.

\section{ACKNOWLEDGMENTS}

The authors would like to thank the Public Transport Organizing Authority of the Paris Region (STIF) for partially funding this research. We also thank Shaoqing Wang for the preparation of maps. 


\section{REFERENCES}

1 Jin, J.G., K.M. Teo, and L.J., Sun. Disruption Response Planning for an Urban Mass Rapid Transit Network. Presented at $92^{\text {nd }}$ Annual Meeting of the Transportation Research Board, Washnigton, D.C., 2013.

2 Zhu, S., and D.M. Levinson. Disruptions to Transportation Networks: A Review. Publis hed in Network Reliability in Practice. Springer, 2012, pp. 5-20.

3 De-Los-Santos, A., G. Laporte, J.A. Mesa, and F. Perea. Evaluating passenger robustness in a rail transit network. Transportation Research Part C: Emerging Technologies, Vol. 20, No. 1, 2012, pp. 34-46.

4 Evans, A.W., and A.D. Morrison. Incorporating Accident Risk and Disruption in Economic Models of Public Transport. Journal of Transport Economics and Policy, Vol. 31, No. 2, 1997, pp. 117-146.

5 Small, K.A. The scheduling of consumer activities: work trips. The American Economic Review,Vol. 72, No. 3, 1982, pp. 467-479.

6 Public transport organizingauthority of Paris region (STIF), Les nouvellesmobilités des Franciliens. Press Report- 2012. http://www.driea.ile-de-france.developpement-durable.gouv.fr RATP, official website. http://travaux-ete-rera.ratp.fr/en/. Accessed July 31, 2015.

8 Fan, T., W.-C. Chiang, and R. Russell. Modeling urban hazmat transportation with road closure consideration. Transportation Research Part D: Transport and Environment, Vol. 35, 2015, pp. 104-115.

9 Pillac, V., C.Guéret, and A. L. Medaglia. An event-driven optimization framework for dynamic vehic le routing. Decision Support Systems, Vol. 54, No. 1, 2012, pp. 414-423.

10 Kattan, L.,A.G. de Barros, and H. Saleemi. Travel behavior changes and responses to advanced traveler information in prolonged and large-scale network disruptions: A case study of west LRT line construction in the city of Calgary. Transportation Research Part F: Traffic Psychology and Behaviour, Vol. 21, 2013, pp. 90-102.

11 Schmocker, J.-D., S. Cooper, and W. Adeney. Metro Service Delay Recovery: Comparison of Strategies and Constraints across Systems. In Transportation Research Record: Journal of the Transportation Research Board, No. 1930, Transportation Research Board of the National Academies, Washington, D.C., 2005, pp. 30-37.

12 Cadarso, L., and A. Marin. Recovery of disruptions in Rapid Trans it Networks with OriginDestination Demand. Procedia - Social and Behavioral Sciences, Vol. 111, 2014, pp. 528-537.

13 Schranil, S. and U.A. Weidmann. Forecasting the Duration of Rail Operation Disturbances. Presented at $92^{\text {nd }}$ Annual Meeting of the Transportation Research Board, Washington, D.C., 2013.

14 Corman, F., A. D'Ariano, and I.A. Jansen. Disruption Handling in Large Railway Networks. Presented at $12^{\text {th }}$ International Conference on Computer Science System Design and Operation in Railways and Other Transit Systems, Beijing, China, 2010.

15 Pender, B., G. Currie, A. Delbosc, and N. Shiwakoti. Planning for the unplanned: an international Review of Current Approaches to Service Disruption Management of Railways. Presented at the $35^{\text {th }}$ Australian Transport Research Forum, Perth, Australia, 2012.

16 Kepaptsoglou, K., and M.G. Karlaftis. Bus bridging Problem in Metro Operations: Mathematical Framework and Decision Support System. Presented at $87^{\text {th }}$ Annual Meeting of the Transportation Research Board, Washington, D.C., 2008.

17 Pender, B., Graham, C., A. Delbosc, and N. Shikawoti. Improving response to Unplanned Passenger Rail Disruption: a New Method to Locate Rail-Replacement Bus Reserves. Presented at $93^{\text {rd }}$ Annual Meeting of the Transportation Research Board, Washington, D.C., 2014.

18 Pender, B., G. Currie, A. Delbosc, and Y. Wang. Proactive recovery from rail Disruptions Through Provision of Track Crossovers and Bus Bridging. In Transportation Research Record: Journal of the Transportation Research Board, No. 2275, Transportation Research Board of the National Academies, Washington, D.C., 2012, pp. 68-76.

19 Chu, F., and A. Oetting. Modeling Capacity Consumption Considering Disruption Program Characteristics and the Transition Phase to Steady Operations During Disruptions. Journal of Rail Transport Planning \& Management, Vol. 3, No. 3, 2013, pp. 54-67. 
20 Krasemann, J. T. Design of an effective algorithm for fast response to the re-scheduling of railway traffic during disturbances. Transportation Research Part C: Emerging Technologies, Vol. 20, No. 1, 2012, pp. 62-78.

21 Lorek, M., S.P. Fekete, A. Kroller, and M.E. Pfetsch. Disruption Management with Rescheduling of Trips and Vehicle Circulations. Presented at the Joint Rail Conference, Pueblo CP, 2011.

22 Sato, K., K. Tamura, and N. Tomii. A MIP-based timetable rescheduling formulation and algor ithm minimizing further inconvenience to passengers. Journal of Rail Transport Planning \& Management, Vol. 3, No. 3, 2013, pp. 38-53.

23 D'Acierno, L., M. Gallo, B. Monte la, and A. Placido. Evaluation of Travel Demand Impacts in the Case of Rail System Failure. Procedia-Social and Behavioral Sciences, Vol. 87, 2013, pp. 75-84.

24 Pender, B., G. Currie, A. Delbosc, and N. Shiwakoti. Disruption Recovery in Passenger Railways: International Survey. In Transportation Research Record: Journal of the Transportation Research Board, No. 2353, Transportation Research Board of the National Academies, Washington, D.C., 2013, pp. 22-32.

25 Kumakawa, K., K. Hara, and T. Koseki.A Novel Train Rescheduling Algorithm for Correcting Disrupted Train Operations in a Dense Urban Environment. Presented at $11^{\text {th }}$ International Conference on Computer System Design and Operation in the Railway and Other Transit Systems, Toledo, Spain, 2008.

26 Cats, O. Multi-agent Transit Operations and Assignment Model. Procedia Computer Science, Vol. 19, 2013, pp. 809-814.

27 Sanchez-Martinez, G.E., H.N. Koutsopoulos, and N.H.M. Wilson. Event-Driven Holding Control for High-Frequency Transit. Presented at $94^{\text {th }}$ Annual Meeting of the Transportation Research Board, Washington, D.C., 2015.

28 Forsgren, M., M. Aronsson, and S. Gestrelius. Maintaining tracks and traffic flow at the same time. Journal of Rail Transport Planning \& Management, Vol. 3, No. 3, 2013, pp. 111-123.

29 Voith, R.P., P.A. Angelides, and A. Ozimek. Consumer response to Service Interruption on the Washington Metro. Presented at $93^{\text {rd }}$ Annual Meeting of the Transportation Research Board, Washington, D.C., 2014.

30 Leurent, F., E. Chandakas, and A.Poulhès traffic assignment model for passenger transit on a capacitated network: Bi-layer framework, line sub-models and large-scale application. Transportation Research Part C. Vol. 47, Part 1, Pages 3-27, 2014. 